\title{
Artigos
}

Carolina Faria Alvarenga' Cláudia Pereira Vianna²

\section{Gênero como uma dimensão de qualidade: uma análise do processo de construção dos Indicadores de Qualidade da Educação Infantil Paulistana}

Resumo: As relações de gênero ganharam visibilidade no enfrentamento das desigualdades no âmbito das políticas educacionais mais recentes. Contudo, um retrocesso em relação à agenda de gênero veta sua menção em vários documentos de políticas educacionais, como os planos de educação, e controla as práticas escolares. Contra essa tendência e permeado por tensões e contradições, tivemos no contexto da Educação Infantil na capital paulista, um movimento oposto: a inserção do gênero na construção dos Indicadores de Qualidade da Educação Infantil Paulistana. Portanto, este artigo, parte de uma pesquisa de doutorado, baseia-se nas articulações teóricas entre Joan Scott e Norbert Elias para analisar o processo de construção dessa política pública educacional que leva para a Educação Infantil um tema polêmico, como o das relações de gênero, e supõe o exame do jogo de disputas, de poder, de tensões, concessões e desafios que configurou tal política.

Palavras-chave: Gênero. Educação Infantil. Política pública. São Paulo. Indicadores de qualidade.

\section{Gender as a dimension of quality: an analysis of the process of construction of Quality Indicators for Child Education of the city of São Paulo}

\begin{abstract}
Gender relations gained greater visibility in the fight against several forms of inequality within the most recent educational policies. However, a setback against the gender agenda neglects its mention in many educational policy documents, such as education plans, and controls school practices. Against this tendency and intertwined with tensions and contradictions, occurred in the context of Child Education in the city of São Paulo an opposite movement: the inclusion of gender in the construction of Quality Indicator for Child Education of the city of São Paulo. The public policy was defined in which gender was introduced as a dimension of quality. Therefore, this paper, part of a doctoral research, is based on the theoretical articulations between Joan Scott and Norbert Elias in order to analyze the process of construction of this public educational policy that leads to Child Education a controversial theme, such as gender relations, and supposes the examination of the game of disputes, tensions, concessions and challenges that shaped such policy.
\end{abstract}

Keywords: Gender; Child Education; Public Policy; São Paulo; Quality Indicators.

\footnotetext{
${ }^{1}$ Mestre e Doutoranda em Educação pela Universidade de São Paulo. Professora Adjunta da Universidade Federal de Lavras. E-mail: carol_alvarenga@ded.ufla.br

2 Doutora em Educação pela Universidade de São Paulo. Professora Associada Sênior da Faculdade de Educação da Universidade de São Paulo. E-mail: cpvianna@usp.br
} 

s caminhos percorridos pelo campo da Educação Infantil no Brasil, desde a Constituição Federal (CF), de 1988, fruto da luta dos movimentos sociais em defesa da infância e dos direitos das crianças e famílias (mães) trabalhadoras, permitem-nos afirmar que, apesar de retrocessos e dificuldades, incluindo a disputa por financiamento, muito foi conquistado. No entanto, Fúlvia Rosemberg (2015) alerta para o grande desafio que ainda temos para implementar a educação de qualidade posta nos documentos construídos ao longo das últimas décadas.

O grande desafio para implementar uma educação infantil democrática e de qualidade no Brasil não depende de melhores diretrizes ou normatização mais ampla e abrangente, mas sim enfrentar o descompasso entre esse ideal, contemporâneo e sofisticado, e o real da prática cotidiana, o desafio entre o normatizado pelos documentos e pelas propostas sofisticadas que elaboramos nessas últimas décadas e as condições sociais, políticas, econômicas e culturais que geram uma sociedade e uma educação infantil ainda intensamente discriminatórias: de classe, gênero, raça, região, localização e idade (ROSEMBERG, 2015, p. 222).

Portanto, ultrapassar o normatizado, em documentos cujas concepções são atuais e contemporâneas no que se refere à noção de qualidade, e avançar na construção de uma Educação Infantil não discriminatória e articulada às relações de gênero, foco desta pesquisa, ainda é um desafio.

As Diretrizes Curriculares Nacionais para a Educação Infantil (DCNEI) foram um avanço para o campo da Educação Infantil, uma vez que, ao orientarem a organização, a articulação, o desenvolvimento e a avaliação para as instituições de Educação Infantil, deram destaque às interações e às brincadeiras como eixos norteadores das práticas pedagógicas que compõem a organização curricular da Educação Infantil, partindo do pressuposto de que bebês e crianças pequenas são sujeitos históricos de direitos e desejos (BRASIL, 2010).

Ao tratar no art. 10 sobre a obrigatoriedade de as instituições de Educação Infantil criarem "procedimentos para acompanhamento do trabalho pedagógico e para avaliação do desenvolvimento das crianças, sem objetivo de seleção, promoção ou classificação", as DCNEI colocam a necessidade de avaliar não apenas o desenvolvimento das crianças, mas também o contexto em que elas estão inseridas. E 
documentos como os Indicadores de Qualidade da Educação Infantil, conhecido como Indique, refletem essa concepção de qualidade que vem sendo construída no âmbito das políticas públicas.

Para nossa reflexão, cabe lembrar que o Indique foi lançado em 2009 com o objetivo de auxiliar creches e pré-escolas de todo o país nos processos de autoavaliação, a fim de garantir um potencial transformador com "práticas educativas que respeitem os direitos fundamentais das crianças e ajudem a construir uma sociedade mais democrática" (BRASIL, 2009, p. 14). Ao ser lançado, duas questões foram suscitadas: "como deve ser uma instituição de educação infantil de qualidade?" e "quais são os critérios para se avaliar a qualidade de uma creche ou de uma pré-escola?” (BRASIL, 2009, p. 13). Ancorado na concepção de qualidade negociada de Anna Bondioli (2004) e diante da possibilidade de muitos caminhos a serem percorridos para o aperfeiçoamento do trabalho educativo nas instituições de Educação Infantil brasileiras, o Indique defende que esse potencial transformador precisa ser construído entre a equipe que atua nas creches e pré-escolas e famílias e comunidade.

Entretanto, apesar dos muitos caminhos possíveis, alguns princípios precisam ser considerados. Um deles é "o reconhecimento e a valorização das diferenças de gênero, étnico-racial, religiosa, cultural e relativas a pessoas com deficiência" (BRASIL, 2009, p. 14, grifos nossos).

Considerando estes pressupostos legais, o município de São Paulo, durante a gestão do prefeito Fernando Haddad, sob a coordenação da professora Sonia Larrubia Valverde, construiu seis documentos que atualmente compõem a política pública da Educação Infantil paulistana: 1) Orientação normativa n ${ }^{\circ}$ 01/2013 - Avaliação na Educação Infantil: aprimorando os olhares; 2) Padrões Básicos de Qualidade na Educação Infantil Paulistana, de 2015; 3) Indicadores da Qualidade da Educação Infantil Paulistana (versão preliminar, de 2015) e Indicadores de Qualidade da Educação Infantil Paulistana (versão final, de 2016); 4) Currículo integrador da infância paulistana, de 2015; 5) O uso da tecnologia e da linguagem midiática na Educação Infantil, de 2015; 6) Magistério - edição especial em comemoração aos 80 anos da Educação Infantil em São Paulo, de 2015.

Este artigo insere-se em uma pesquisa de Doutorado em andamento, cujo objetivo é compreender o processo de construção de um desses documentos, qual seja, os Indicadores de Qualidade da Educação Infantil Paulistana (doravante "Indicadores..."), uma vez que toma por base o Indique, mas insere uma dimensão específica que aborda as questões de gênero.

Assim como o Indique, os "Indicadores..." são um documento de autoavaliação institucional participativa e organizam-se em dimensões, indicadores e descritores. Em cada dimensão, há um texto de apresentação, composta por quatro ou cinco indicadores, que são avaliados a partir de descritores (questões), com as cores vermelha, amarela ou verde. Estas questões são debatidas e respondidas em pequenos grupos, seguidos de uma plenária final, em um dia específico do ano letivo em que cada creche ou pré-escola convida a comunidade para um momento de autoavaliação e, posteriormente, para a realização de um plano de ação construído com base nos descritores vermelhos e amarelos, principalmente. 
Partimos das articulações teóricas entre Joan Scott e Norbert Elias para analisarmos o processo de construção dessa política pública educacional que leva para a Educação Infantil um tema polêmico, como o das relações de gênero, e supõe o exame do jogo de disputas, de poder, de tensões, concessões e desafios que configurou tal política. Modelos de jogos são usados para explicar esses entrelaçamentos e são muito úteis à imaginação sociológica, como afirma Elias (2008). São modelos de jogos de competição, como o xadrez, o tênis e o futebol. As regras são parte importante desses jogos e, em todos eles, fazem parte duas ou mais pessoas que se relacionam umas com as outras e medem suas forças. Há sempre uma disputa de poder. Porém, poder é entendido não como um amuleto que alguém carrega. Ao contrário, é "um elemento integral de todas as relações humanas" (ELIAS, 2008, p. 80). O poder, portanto, é relacional e não unilateral e estático. O equilíbrio de poder, ora mais estável, ora mais instável, é uma ocorrência cotidiana.

Ao tratar de uma relação de interdependência entre os indivíduos e entre indivíduos e sociedade, o autor cria o conceito de configuração. Para ele, indivíduo e sociedade estão em níveis diferentes, mas são inseparáveis do mundo humano. Uma configuração forma um "entrançado flexível de tensões" e a interdependência dos indivíduos pode se dar como aliados ou adversários. É como um jogo. E, nesse jogo, "há um equilíbrio flutuante e elástico e um equilíbrio de poder, que se move para diante e para trás, inclinando-se primeiro para um lado e depois para o outro" (ELIAS, 2008, p. 143).

As tensões ou as relações de poder, segundo Elias (1994), são o motor da história. São intrínsecas das relações humanas e impulsionam as mudanças sociais. A sociedade é, ao mesmo tempo, muito firme e muito elástica. Há um continnum sócio-histórico de permanentes mudanças e conservações no qual estão inseridos os indivíduos. E, nela, as decisões individuais são sempre inseridas na rede social. Como em um jogo de cartas, por exemplo, há uma tradição e um jeito próprio de se jogar, mas a forma, o ritmo e as ações dependem do grupo de indivíduos interdependentes que jogam no momento (ELIAS, 2008).

Elias, ao construir a noção de configuração social, critica duas visões sobre a história. De um lado, uma história que enaltece os indivíduos isoladamente, e, de outro, uma história que sobrevaloriza o papel da estrutura social. Para o autor, os acontecimentos históricos podem ter, muitas vezes, influência de decisões pessoais. A margem de decisão individual depende, porém, dos instrumentos de poder e da posição social a qual a pessoa ocupa e é sempre variável em sua natureza e extensão. Ela é sempre limitada, uma vez que os indivíduos estão ligados de forma interdependente. A história é, portanto, "um sistema de pressões exercidas por pessoas vivas sobre pessoas vivas" (ELIAS, 1994, p. 47).

Para este debate, na busca de compreender o processo de articulação de uma política pública de Educação Infantil na perspectiva de gênero, ou seja, as tensões e os conflitos inerentes a uma teia que se entrelaçou durante esse jogo, é imprescindível contar com a contribuição da historiadora feminista e estadunidense Joan Scott (1995) que define o conceito de gênero como uma categoria de análise.

Para Scott (1995, p. 86), gênero é "constitutivo de relações sociais baseadas nas diferenças percebidas entre os sexos", por meio do qual estão implicados quatro elementos que se relacionam entre 
si. A partir da organização social, cultural, histórica, política e econômica, organizam-se símbolos, constituem-se conceitos normativos, constroem-se instituições sociais e políticas e identidades subjetivas.

Como historiadora, Scott critica os usos do gênero até então feito por teorias feministas ao afirmar que apenas a descrição das relações desiguais entre homens e mulheres não carrega força suficiente para questionar e mudar os paradigmas existentes. Scott (1995, p. 84), em diálogo com Jacques Derrida, ressalta a "necessidade de uma rejeição do caráter fixo e permanente da oposição binária, de uma historicização e de uma desconstrução genuínas dos termos da diferença sexual”. Nesse sentido, é preciso problematizar a oposição e a hierarquia entre homens e mulheres e perceber a interdependência entre eles e elas, assim como a complexidade e a heterogeneidade das relações sociais de gênero.

Para avançar na compreensão da oposição e da hierarquia entre os sexos para uma mudança na organização social, Scott compõe sua definição de gênero também como "uma forma primária de dar significado às relações de poder" (SCOTT, 1995, p. 86). A autora baseia-se no conceito de poder de Michel Foucault, ao afirmar que todas as relações sociais são relações de poder, percebidas como "constelações dispersas de relações desiguais, discursivamente constituídas em 'campos de forças' sociais", e não como algo "unificado, coerente e centralizado" (SCOTT, 1995, p. 86).

Ao relacionar gênero e poder, Scott mostra como a política constrói o gênero e como o gênero constrói a política e exemplifica a partir da relação com o governo e o Estado Nação, em um momento em que a história política considerava gênero como uma "categoria antitética aos negócios sérios da verdadeira política" (p. 89). Ao se falar sobre a guerra, por exemplo, sua legitimidade se apresentava intrínseca a um dos signos associados ao que é considerado masculino: a virilidade (em contraposição a uma suposta vulnerabilidade de mulheres e crianças). Por isso, gênero precisa ser considerado "um meio de decodificar o sentido e de compreender as relações complexas entre diversas formas de interação humana" (p. 89).

Para uma análise história, a política é um dos domínios em que gênero pode ser usado para compreender como o poder foi concebido e legitimado. E "se as significações de gênero e de poder se constroem reciprocamente, como é que as coisas mudam"? (SCOTT, 1995, p. 92). Muitas podem ser as origens das mudanças, mas são os processos políticos que as alimentarão - "político no sentido de que atores diferentes e significados diferentes lutam entre si para assegurar o controle" (p. 93). A natureza desses processos, com seus atores, atrizes e ações, situadas no tempo e no espaço, farão emergir uma nova história.

Nesse sentido, ao problematizarmos a inserção de gênero nos Indicadores de Qualidade da Educação Infantil Paulistana, articulamos os conceitos de Elias e Scott para a compreensão do processo de construção do documento paulistano. Nos termos de Elias, entender a configuração dessa política, os sujeitos que, de forma interdependente, dela participaram, em um campo minado de tensões e jogos de poder, remete-se também ao desafio teórico proposto por Scott: a utilização do gênero como uma categoria de análise. 


\section{Sobre a cozinha da inserção de gênero na Educação}

Para captar as tensões e os desafios do processo de construção do documento, foi entrevistada parte da equipe de profissionais da Secretaria Municipal de Educação (SME) da Prefeitura de São Paulo que compôs uma Comissão Ampliada para a escrita dos "Indicadores..." compuseram essa comissão, todas mulheres, as entrevistadas foram as professoras responsáveis pela escrita da "Dimensão 5 - Relações étnico-raciais e de gênero" - Carolina Duarte, Elaine Conceição, Kelly Silva, Edilene Ribeiro, Renata Oliveira, as assessoras externas da SME para a elaboração do documento Maria Malta Campos e Bruna Ribeiro, e a então diretora da Diretoria de Orientação Técnica de Educação Infantil (DOT-EI)- Sonia Larrubia.

Todas as entrevistadas relataram que a inserção de gênero no documento foi um processo tenso.

Bastante tenso, porque existe um processo de negação, isso nas diferentes instâncias. A gente poderia dizer que foi um processo consensual. Não, existe um tensionamento em todas as dimensões. Diz. respeito ao desconhecimento das marcas discriminatórias na infância, ou mesmo praticadas por parte dos educadores; então, existe um silenciamento. (Elaine) ${ }^{4}$

Foi tenso, porque causou também estranbeza no grande grupo; porque a gente teve que bancar, a gente teve que fazer defesas para acontecer. Depois que o grupo aceitou, foi tranquilo e a gente teve bastante apoio. (Edilene)

Apesar de as mulheres responsáveis pela elaboração dos "Indicadores..." possuírem proposições políticas semelhantes e concepções de infância e Educação Infantil ancoradas em uma pedagogia que respeita as crianças como sujeitos de direitos e desejos, elas tinham também diferentes protagonismos e trajetórias, o que resultou em um debate permeado de tensões e negociações para que se chegasse a um acordo sobre três pontos polêmicos: 1) a necessidade de uma nova dimensão que abordasse as relações étnico-raciais, num primeiro momento, dando visibilidade ao tema e não apenas transversalizando nas outras dimensões; 2) a definição de quais marcadores sociais comporiam com raça/etnia o debate sobre a diversidade e, nesse momento, o grupo assume as questões de gênero; e 3) a definição de um título para essa dimensão que representasse as concepções do documento acerca do debate realizado.

Essas decisões não foram lineares e as entrevistas revelam que as definições foram sendo amadurecidas a cada etapa do processo. Como o trabalho está em andamento, nosso desafio para este artigo foi apresentar, de forma ainda incipiente, o que provocou as tensões e as polêmicas entre essas mulheres no processo de proposição, negociação e elaboração do documento. Como disse uma das entrevistadas: "A gente se reunia em subcomissão, se debruçava um pouco, depurava... eu brincava com elas que a gente estava farendo algum doce, que a gente ia depurando o doce. Um doce bom, aquele doce caseiro, é quando ele fica bem depurado." (Sonia). É preciso depurar a questão de gênero na educação. Como ela é ainda uma ponta de lança e não é considerada necessariamente crucial, provoca ainda hoje muitas tensões.

\footnotetext{
${ }^{3}$ O documento foi construído entre os anos de 2014 e 2015. Após uma aplicação voluntária do Indique em 441 unidades educativas em 2013 e 2014 e a realização de seminários regionais com a participação de supervisoras/es e coordenadoras/es pedagógicas/os para discussão sobre a proposta de elaboração de um instrumento de avaliação de contexto, foi apresentada uma primeira versão do documento paulistano em 2015. A versão preliminar foi entregue em formato digital a todas as unidades de Educação Infantil de São Paulo, incluindo as conveniadas, e, novamente, foram realizados seminários regionais para debate e envio de sugestões. Revisada pela Comissão de escrita foi publicada a versão final no início de 2016.

${ }^{4}$ Optamos por colocar os trechos das entrevistas em itálico para se destacarem de outras citações.
} 


\section{Sobre o desafio da interseccionalidade entre raça e gênero}

Apesar de o foco da pesquisa ser gênero, foi preciso estender o olhar para as relações étnicoraciais, especialmente porque, a partir das entrevistas, ficou explícito que a proposta da "Dimensão 5" nasceu com o debate racial. No início, as questões de gênero não estavam presentes, mas elas ganharam força a partir do argumento sobre a importância da interseccionalidade entre raça e gênero, principalmente a partir de relatos das próprias professoras sobre suas experiências com crianças no cotidiano das creches e pré-escolas.

No entanto, ainda que gênero tenha sido inserido como parte de uma dimensão específica e também de forma transversal, principalmente a partir de uma linguagem inclusiva em todo o documento, um olhar mais atento constata que as questões étnico-raciais se sobressaem às de gênero: tanto em relação ao número de descritores que abordam as questões étnico-raciais, quanto às referências a documentos legais e bibliografias. Portanto, como pesquisadoras, olhar para os "Indicadores..." e perceber que as questões étnico-raciais se sobressaíam às de gênero não era suficiente para chegar à origem do debate. Foi preciso ouvir as professoras para compreendermos essas tensões.

Em 2014, com a criação da Comissão Ampliada para a escrita do documento paulistano, "se inicion uma discussão sobre: Como seriam essas dimensões? A princípio, nós trouxemos a demanda de que precisariamos inserir algumas discussões; em especial, a dimensão racial, que é uma discussão, na infância, que já se fazia". E, a partir da análise do Indique, percebeu que "se discutia muito pouco essa dimensão racial: Como é que meninas e meninos negros vão se constituir dentro desse espaço?". (...) "Essa intersecção acaba caminhando o tempo inteiro, de gênero com a questão racial, mas, a princípio, a discussão foi racial" (Elaine).

Carolina reitera que "nesse momento, não tinha a questão de gênero" e "foi importante ter essa temática num documento da Prefeitura de São Paulo que tratasse sobre a questão racial", considerando que "o racismo é estruturante de nossa sociedade, desde os bebês". Porém, ao fazerem uma autoavaliação, perceberam que estavam "deixando as questões de gênero para trás" e, mesmo com uma "defasagem" não poderiam deixar de ter um "olbar interseccional entre raça e gênero".

Quem são as crianças menos abraçadas, menos apreciadas? Pensando nas crianças de Fundamental, quem são considerados indisciplinados? A questão da evasão, da produção de material, da ilustração do material, das histórias que tražem! O quanto isso está misturada a questão da raça e gênero! (Carolina)

Todas as entrevistadas concordam que prevaleceu a questão étnico-racial. Kelly afirma: "eu acho que a questão étnico-racial, realmente, veio mais forte, mas a gente falou: Não, a gente tem que trazer essa questão do gênero, porque não está dando para descolar'. Então, nas nossas discussões, nas nossas conversas, isso ficava muito evidente".

O desafio de interseccionar gênero e raça/etnia foi, em parte, contemplado nos "Indicadores...". Para justificarem essa intersecção, as entrevistadas apontam vários exemplos de como essas questões estão ligadas.

Os meninos, principalmente, negros, dentro das unidades, sempre são vistos como os bagunceiros, como os mal-educados. Eles são, muitas vežes, negligenciados: "Ai, que isso aí não tem jeito, vai virar 
bandido". Então, não dá para descolar, percebe? E as meninas, "as meninas vão ser as diaristas de amanhã". Então, a gente não consegue descolar, é muito ligada essa questão do gênero e da raça, o feminino do masculino, é como essa segregação, essa dicotomia, ela aparece; e como é isso com as crianças bem pequenas, porque as crianças percebem isso, elas são afetadas por isso a todo o momento. (Kelly)

E nessa discussão bem tensa, a gente achou necessário pensar nesse viés raça e gênero, porque quando você olha para as meninas, a questão da exclusão tem um componente racial fortíssimo. Não são só meninas, meninos e meninas negras. Você tem os meninos negros com o estigma de serem discriminados, bagunceiros, desde pequenininhos. E as meninas negras, também, desde pequenininhas, com a questão da sexualidade. Então, esses marcadores sociais da raça também vêm junto com gênero. Então, a gente falou: "Olha, então ficam essas questões, porque a gente acha importante". (Carolina)

Eu visitei um município [do estado] de São Paulo, na Educação Infantil, e uma criança de cinco anos falou para a professora: "Ah, mas eu vou me desenhar bonita e loira". Uma negra, de cinco anos, que se desenhou loira, com olhos azuis, bem o estereótipo mesmo. Eu penso que a gente tem muita responsabilidade, não é só da escola, mas também da escola, não é? Que livros que nós estamos oferecendo? Que brinquedos nós estamos oferecendo? Que práticas? Para que uma criança de cinco anos já tenha formado, ou não formado, ou formado dessa forma equivocada sua autoimagem. Então, penso que isso é papel da educação. Ainda mais na Educação Infantil, penso que é fundamental, que esse momento onde a criança está construindo a identidade, que isso seja feito de uma forma que ela possa construir de uma forma positiva. (Bruna)

Logo, a inserção de gênero em uma dimensão que, inicialmente, denuncia as relações étnicoraciais, é justificada pelas professoras em função da intersecção desses dois marcadores sociais, especialmente nas creches e pré-escolas (FINCO; OLIVEIRA, 2011).

Elaine lembra que, em um dos seminários regionais em que se discutia a construção do documento, a mãe de uma criança de uma unidade educacional, que também é pesquisadora, as questionou sobre a opção de juntar as duas questões em uma dimensão:

"Bem, mas a gente pensa que são dimensões que necessitam de uma imersão, por que elas foram juntadas? Porque em alguns pontos vocês conseguem unir essa discussão, mas em alguns pontos é necessário que se faça essa distinção, para que mais uma vez. não haja uma mistura que acaba não colaborando muito para a discussão".

O grupo respondeu que, mesmo tendo intersecções, "conceitualmente, o ideal seria que a gente tivesse, então, uma dimensão para pensar as relações étnico-raciais e uma dimensão para pensar as questões de gênero". Porém, as professoras alegam que havia um limite em relação ao tamanho do documento. Em um quadro comparativo entre a versão nacional e a paulistana, esta última é maior, visto que inseriu duas novas dimensões ${ }^{5}$, apesar do esforço de síntese da Comissão, já que havia sido uma demanda da própria Rede não ter um documento extenso. Logo, "para que a gente não perdesse o espaço de discussão, a gente preferiu aglutinar mais, mas manter, inclusive, na titulação para que todos vissem que foi uma discussão de gênero" (Elaine).

Essa fala nos mostra algumas das disputas presentes na construção do documento, assim como o "currículo, [que] é sempre um universo de disputas" (Elaine). Todas as professoras ressaltam que, no debate sobre a relação entre as questões de gênero e étnico-raciais pesou a ordem prática. Quanto maior o documento, mais difícil seria a operacionalização, a logística e o tempo para discussão. E essa foi uma cobrança da Rede, presente na fala das entrevistadas: a dificuldade com o tamanho e o tempo para aplicação.

Uma das professoras ressalta que, mesmo tendo um foco menor em gênero, o desafio foi tentar "fazer os descritores com muita qualidade para ter um peso" (Edilene). Apesar de ter que fazer escolhas, o objetivo

${ }^{5}$ Foi inserida, além da "Dimensão 5 - Relações étnico-raciais e de gênero", a "Dimensão 2 - Participação, escuta e autoria de bebês e crianças". 
dos "Indicadores..." é suscitar a discussão: "a ideia é que, a partir desse básico, cada unidade se aprofunde e amplie esses direitos e essas discussões" (Bruna). Outra professora ressalta que "mesmo se a questão racial se sobrepõe a de gênero, aquelas poucas perguntas que estão lá, en acho que fažem grande diferença para suscitar discussões na escola" (Carolina), uma vez que, muitas vezes, o debate é ainda muito "latente: a gente está pensando no início, no início, no início da discussão, quando você fala: "mas tem brinquedo de menino e de menina?", ou ainda, "fila, não é exceşão, ainda é regra!".

A compreensão de que as ações tomadas no decorrer do jogo não podem ser explicadas em si mesmas, mas precisam ser consideradas na estrutura do jogo (ELIAS, 2008), traz pistas para entender o porquê de algumas decisões, como, por exemplo, aproveitar uma dimensão para inserir duas questões importantes, mesmo que uma tenha se sobressaído à outra.

Carolina atribui a ênfase à questão racial às trajetórias das professoras que compuseram a "Dimensão 5": "nenhuma de nós tinha leituras específicas sobre a questão de gênero e a questão de gênero entrou nesse contexto de escrita. Nós temos consciência de que precisaria melhorar". E no jogo de disputa por espaço, considerando as questões de ordem práticas já mencionadas, fica o que tem mais força no momento: "também tem o jogo interno. As escolas pontuaram que eram muitas questões; então, você tira".

No entanto, apesar da maior prevalência das questões étnico-raciais no documento, não há como negar a importância desta política pública para a agenda de gênero na Educação Infantil paulistana, uma vez que a "Dimensão 5 - Relações étnico-raciais e de gênero" assume o compromisso com a promoção da igualdade, considerando aspectos do cotidiano presentes no currículo e na prática pedagógica, nos relacionamentos e atitudes entre adultos e crianças e crianças e crianças, na atuação das/dos profissionais e na construção positiva das identidades. Como afirma uma das professoras: "conceitualmente, a gente poderia explorar muito mais as duas dimensões se elas fossem de forma separada, mas nas circunstâncias atuais que a gente tinha, era preferivel a gente manter, garantindo esse lugar das interseçães, do que optar pela exclusão da dimensão, em si" (Elaine).

\section{Sobre a tensão entre o geral e o específico}

Foi um debate quente! O primeiro debate foi: Por que isso tem que se transformar numa dimensão? E ai, nesse grande debate, a gente chegou à conclusão que era para ter uma dimensão, porque com aquela dimensão um grupo da escola iria parar para pensar só aquilo. Por que qual era a questão? Era na plenária; porque, se você dilui, na hora que vai para a plenária, isso pode desaparecer, desaparecer, ninguém mais fala sobre isso. Então, a primeira questão foi essa e a gente chegou a essa questão, que era importante uma dimensão. (Renata)

Foi difícil! Não foi fácil garantir essa dimensão dentro do processo. Foi bem difícil a criação e a garantia dela, porque esse é um assunto que podia permear todo o documento. Na verdade, deveria permear todo o documento, e a gente fez essa tentativa, mas a gente quis marcar mesmo uma dimensão para trazer à tona, como uma marcação, de que esse seria um tema que deve ser tratado dentro das unidades. (Kelly)

As entrevistas com as profissionais que compuseram a "Dimensão 5" permitiram que captássemos as muitas tensões vivenciadas no momento de discussão e definição de como seria o 
documento para que "ficasse com a cara da cidade de São Paulo e com as especificidades que nós vínhamos trabalhando aqui na gestão em São Paulo” (Sonia).

A inclusão das crianças com deficiência na dimensão que contemplaria a diversidade foi fruto de muitos debates ao longo do processo de construção dos "Indicadores...".

Em todas as escolas que a gente acompanhou mais de perto, a pessoa falava: "Mas cadê a criança com deficiência?". Porque isso é um problema para as escolas, eles têm apoio, a Prefeitura dá apoio para o trabalho com as crianças com deficiência, mas os professores têm muita dificuldade de lidar, é uma questão ainda que não está bem resolvida.(Maria)

Para tanto, foi inserida no início dos "Indicadores..." uma explicação sobre esta decisão, a partir de justificativas legais e pedagógicas, já construídas pelo MEC e pela SME-SP. Destaca-se que a Educação Infantil é entendida como um "um espaço privilegiado para as vivências das diversidades, pois é pensado, planejado e constantemente construído e revisitado com e para todos os bebês e todas as crianças (SME, 2013), tendo como princípio o respeito às infâncias e suas especificidades" (SÃO PAULO, 2016, p. 9). Por isso, uma das professoras destacou que a subcomissão defendeu que não deveria haver uma "dimensão específica para as crianças com deficiência, visto que elas são crianças com deficiência, mas elas são negras, brancas, meninos e meninas" (Carolina).

Outro depoimento reitera que, apesar de tratar da diversidade, a Educação Especial, nessa perspectiva de uma Educação Inclusiva, tal como aponta os documentos citados, "deveria permear todas as dimensões e não ter uma destacada, até porque a história da Educação Especial difere muito desses processos discriminatórios, no que diz respeito a gênero e raça, que sempre são silenciados, ou pouco discutidos ou mesmo ignorados" (Elaine). Logo, a Educação Especial, na perspectiva da inclusão, segundo o próprio documento,

[...] se efetiva de maneira transversal na Educação Infantil - assim como em outras modalidades da educação - na organização de recursos e estratégias de acessibilidade, eliminando as barreiras que possam dificultar o acesso a todas as atividades, vivências e experiências ofertadas para a educação dos bebês e das crianças com deficiência, transtornos globais do desenvolvimento - TGD e altas habilidades e superdotação AHSD (MEC, 2008) (SÃO PAULO, 2016, p. 9).

Nesse sentido, a partir dos argumentos da subcomissão da "Dimensão 5" e o parecer da especialista da SME/DOT Educação Especial, decidiu-se por inserir a Educação Especial na perspectiva da Educação Inclusiva de forma transversal, mesmo tendo a clareza de que "é uma questão que ainda não está bem resolvida" (Maria).

Outra questão importante de ser incluída na diversidade seria sobre os imigrantes, pois tem mobilizado as unidades: "em São Paulo, hoje, temos imigrantes bolivianos, temos imigrantes paraguaios, temos imigrantes do Haiti, temos imigrantes da África; se for aqui, na região central da cidade, as creches e as pré-escolas têm crianças falando várias línguas” (Maria). Entretanto, a assessora salienta que:

[...] eu achava que tendo o enfoque da diversidade, você poderia tratar de várias questões, que são questões que afligem o trabalho da rede. Então, quando você coloca étnico-racial, você está vendo uma vertente, talvez a mais importante, talvez a mais marcante de todas, no Brasil; mas tem outras que a rede também tem dificuldade de lidar, por exemplo, a questão dos imigrantes (Maria).

No entanto, como um dos princípios do trabalho, segundo as próprias entrevistadas, era valorizar o que as pessoas da Rede estavam produzindo, a assessoria entendeu que deveria acatar, apesar de 
considerar que seria importante potencializar o debate sobre a diversidade a partir de outras vertentes. Logo, a defesa das professoras em dar visibilidade às questões de raça/etnia e gênero refere-se ao longo e quase permanente debate sobre a tensão entre o geral e o específico presente na militância feminista, mas que também aparece na educação.

Mais uma vez, essa disputa pode ser percebida a partir do que Elias afirma: "à medida que diminuem as diferenças de poder entre indivíduos e grupos interdependentes, se torna decrescente a possibilidade de quaisquer participantes, por si próprios ou enquanto grupo, estarem aptos a influenciar o decurso global do jogo" (2008, p. 104). Mesmo que a posição das professoras não fosse antagônica à posição da gestora e das assessoras, os lugares que elas ocupavam nesse jogo as colocavam em níveis diferentes, nos termos de Elias. Porém, como um dos princípios da construção do documento era valorizar a participação das professoras da Rede, a diferença de poder entre esses níveis teria se tornado menos desigual à medida que o documento foi sendo produzido.

Um debate silenciado na "Dimensão 5" e que se articula estreitamente com as questões de gênero foi em relação à articulação entre sexualidades e infâncias. Uma das professoras comenta:

Nós chegamos até discutir, mas a gente avaliou que essas outras questões eram mais relevantes do que essa questão da sexualidade, porque a questão da sexualidade a gente já discute na escola, a gente é obrigado, pelo fato das crianças serem pequenas, delas estarem se descobrindo. Então, a gente avaliou; a gente, assim, na verdade, a gente nem fez uma discussão muito grande nessa questão; o que a gente queria pautar mesmo era essa questão da diferença de tratamento de menino e de menina, e que a menina acabava sempre sobrando, e a questão étnico (Edilene).

Apesar de a professora dizer que já discutem sobre sexualidade nas instituições de Educação Infantil, cabe-nos perguntar: qual é a perspectiva? Os corpos das crianças são vistos como corpos marcados por gênero, raça/etnia e classe social? A forma como meninos e meninas vivenciam seus corpos passa pela relação entre sexualidades e infâncias (RIBEIRO, 2008).

Há descritores em outras dimensões que se remetem aos corpos dos bebês e das crianças, porém, dependendo da forma como for conduzido o debate, o que se refere à sexualidade e gênero pode ficar apagado: "4.1.2 As educadoras e os educadores conversam com os bebês e as crianças na troca de fraldas, roupas, calçados, alimentação e banho, valorizando o cuidar e o educar integralmente como momentos privilegiados para interação, acolhimento e afetividade?” (SÃO PAULO, 2016, p. 42).

O banho é visto como um momento privilegiado para "interação, acolhimento e afetividade" entre educadoras e educadores e os bebês e as crianças, mas também como um momento de descoberta e prazer? (RIBEIRO, 2008). Esses momentos podem ser também reveladores de sinais de violências sexuais sofridas pelos bebês e crianças, como salientam Lívia Faria e Marina Castanheira: "No momento do banho muitas são as possibilidades de (des)prazeres no escorrer da água sobre o corpo e mesmo na concepção do banho apenas como momento de higiene pessoal. Assim, muitas podem ser as descobertas na relação com o próprio corpo e com o corpo de outros” (2013, p. 5).

Apesar de as professoras trazerem inúmeros exemplos de seus cotidianos repletos de discriminação de gênero, o que mostra um olhar atento, poderíamos afirmar que o não aprofundamento em uma concepção de uma educação na perspectiva das sexualidades e gênero é em decorrência da 
configuração estabelecida no processo de construção do documento? Ou seja, havia um envolvimento menor do grupo das profissionais com o debate de gênero na Educação Infantil.

Partindo do pressuposto de que já estava pactuado que as relações étnico-raciais e de gênero seriam contempladas no documento, fortaleceu-se o debate sobre a importância de transversalizar e/ou dar visibilidade em uma dimensão. As questões de gênero já estavam sinalizadas em inúmeros documentos nacionais, como, por exemplo, o Referencial Curricular Nacional para a Educação Infantil, de 1998, as DCNEI, de 1999 e a versão mais atual de 2009, e os Parâmetros Nacionais de Qualidade para a Educação Infantil, de 2006 (FINCO, 2010).

No entanto, no Indique, estavam diluídas. A revisão das DCNEI e a publicação do Indique são do mesmo ano: 2009. No entanto, apesar de as DCNEI sinalizarem que as propostas pedagógicas devem contemplar as questões de gênero e étnico-raciais como uma das suas funções sociopolíticas e pedagógicas, no Indique, esse debate foi transversalizado nas sete dimensões.

Construindo novas formas de sociabilidade e de subjetividade comprometidas com a ludicidade, a democracia, a sustentabilidade do planeta e com o rompimento de relações de dominação etária, socioeconômica, étnico-racial, de gênero, regional, linguística e religiosa (DCNEI, BRASIL, 2009, p. 2).

No Indique, o termo gênero aparece no documento uma vez, acompanhado das relações étnicoraciais, quando são destacados aspectos importantes ao se fazer um diagnóstico sobre a qualidade de uma instituição de Educação Infantil: "reconhecimento e a valorização das diferenças de gênero, étnico-racial, religiosa, cultural e relativas a pessoas com deficiência" (BRASIL, 2009, p. 14).

Portanto, para a Comissão, "era necessário que houvesse uma dimensão específica para que, assim, chamasse a atenção dessas questões, já que a gente achava que não estavam bem resolvidas no trabalho que a gente desenvolvia na Rede" (Sonia). No início do debate, consideraram que essas questões poderiam estar em todas as dimensões, porém, perceberam que o assunto poderia "ser camuflado diante de todas as outras dimensões" (Kelly), "principalmente no momento da plenária [momento final da autoavaliação institucional realizada nas unidades educativas após discussões sobre cada dimensão]”(Renata).

O ponto positivo de transversalizar seria a possibilidade de chamar a atenção para a questão em todas as dimensões. Porém, ao mesmo tempo, corria-se o risco de "desaparecer, ninguém mais falar sobre isso" (Renata). A decisão foi, portanto, construir uma dimensão específica, ao mesmo tempo, transversalizando as questões de gênero em todas as outras dimensões. Ao buscarmos pela temática de raça/etnia nas outras dimensões, há apenas uma referência à inclusão e ao respeito às diferenças "(socioeconômica, étnica, de gênero, diversidade sexual, religiosa, crianças com deficiências, transtornos globais do desenvolvimento e altas habilidades/superdotação)" no projeto político pedagógico, sem, no entanto, mencionar a diferença racial. Em outros descritores, há menções ao reconhecimento às diferenças individuais, em respeito à diversidade.

Com relação a gênero, uma preocupação destacada foi em relação à linguagem: destacar as mulheres na linguagem, em todos os descritores - educadoras, professoras, gestoras, meninas - e "a gente até colocou a questão de esse feminino estar em primeira instância, porque eu vou considerar com quem eu estou falando" 
(Elaine). Na "Dimensão 4 - Interações", por exemplo, “4.2.3 As educadoras e os educadores percebem se os bebês e as crianças se sentem pertencentes ao grupo e à Unidade Educacional?" (SÃO PAULO, 2016, p. 43).

Sonia ressalta que esse cuidado em escrever "educadores e educadoras, meninos e meninas" também esteve presente em todos os outros documentos produzidos em sua gestão. "E se não encontrar é porque escapou. Até porque a gente precisa de policiar, às vezes, para que isso não ocorra, a forma como a gente escreve e coloca professores".

De fato, ao analisarmos todo o documento, podemos dizer que "escapou" algumas vezes. "Meninos e meninas" ou "meninas e meninos" são citados apenas duas vezes fora da "Dimensão 5". Na "Dimensão 1 - Planejamento e gestão educacional", o texto inicial, ao se referir aos vários segmentos que devem estar envolvidos na construção do Projeto Político Pedagógico, inviabiliza as mulheres: "é necessário o envolvimento dos vários atores que compõem a Unidade Educacional (pais, professores, funcionários, bebês e crianças) em todas as formas de sua organização" (SÃO PAULO, 2016, p. 29).

Apesar de todo o cuidado e preocupação destacados pela entrevistada, poderíamos justificar essa diferença de tratamento com a linguagem em decorrência de o documento ter sido escrito a muitas mãos e por não ter, em todas as subcomissões, profissionais que não considerem a inserção do feminino na linguagem como algo menor?

Nestes exemplos, o que nos chama a atenção é que, apesar da opção política por uma escrita feminista, a concretude da linguagem, ancorada em uma lógica heteropatriarcal (ACORDO, 2012), nos trapaceia. Muitas vezes, essa "escrita feminista é vista como mero capricho, algum tipo de fetichismo radical que, pela censura da palavra, exprime a angústia da opressão” (p. 142). O Acordo Queerográfico "resultado de um debate coletivo para novas falas e novas escritas" - problematiza e amplia o papel da linguagem para além da comunicação. A linguagem é também experiência.

E é face a este papel da linguagem, que encontramos como tecido político, como construtor do mundo para além do comunicador deste, e que, numa perspectiva geral de análise política, encontramos como perpetuador do status quo, que emerge a urgência de uma nova prática linguística, escrita e oral, e, com ela, de uma nova prática de pensamento (ACORDO, 2012, p. 142).

Portanto, assumir uma nova linguagem nos documentos que compõem uma política pública para a Educação Infantil é opor-se ao estabelecido.

Ana Lúcia Goulart de Faria (2006, p. 287) insiste que "a superação da desigualdade com certeza passa pela educação desde a primeiríssima infância em espaços coletivos na esfera pública convivendo com as diferenças". A fala de Elaine realça essa importância da educação na superação das desigualdades e pondera que o grupo considerou que o título precisaria contemplar as discussões que tinham sido realizadas e a concepção teórica assumida.

Então, ai sim, a gente traria essas duas dimensões, que precisam ser discutidas na infância, e que ambas têm os seus silenciamentos, às vezes por razões distintas e às vezes por razões concomitantes. (...) E ao mesmo tempo, ficou, naquela época, no grupo, até essa ideia suspensa, que a gente colocaria diversidade. $O$ acúmulo de discussão na área nos diz, que se a gente não der nome, isso implica em várias coisas; porque nomear também quer dizerer de que relações a gente está falando. Então, a partir 
disso a gente apresentou como uma proposta que essa dimensão se chamasse Relações Étnico-Raciais e de Gênero. (Elaine)

Antes, portanto, de se chegar ao título Relações Étnico-Raciais e de Gênero, questionaram-se: "Vai ter diversidade? Vai ter desigualdade? Como é que a gente nomina isso? Diversidade Étnico-Racial? Não. Desigualdade Étnico-Racial? Não. Mas como é que a gente quer chamar isso?’ (Elaine). Renata acrescenta:

\begin{abstract}
Quando a gente chega a Relações Étnico-Raciais, quando a gente chega a "relações", elas podem ser iguais e desiguais; e a gente achou que assim o titulo dava conta do debate que se tinha feito, para não dizer que a gente estava falando de diferença, porque isso é um negócio que pega na rede, todo mundo trabalha com a diferença. É um negócio espetacular. Então, assim, eu acho que se eu ler um livro da Frida, "Ó, eu já falei lá da diferença da mulher poderosa", mas eu leio o restante do ano todo das princesas que ficam na torre esperando o cara. (Renata)
\end{abstract}

A professora, ao trazer a noção de diferença, sinaliza um aspecto importante que a perpassa: as relações de poder.

\begin{abstract}
Então, a gente faz̦ia muito debate sobre o que é diferença e o que é desigualdade, as diferenças existem e nós valorizamos as diferenças. Só que a partir do ponto que essa diferença ganha uma conotação de poder, porque, de verdade, existe o poder, ela vira uma desigualdade. É quando eu digo que, na sociedade, homem vale mais do que mulher, branco vale mais que negro. Ai eu já estou em outro patamar é é ai que entra a relação de poder que a gente queria colocar aqui dentro, porque não vira só diversidade, porque no campo da diversidade, "olha, todo mundo aqui contou uma história de índio, todo mundo um dia contou uma história de negro”, só que são episódicas. (Elaine)
\end{abstract}

A partir desta fala, é possível perceber que o documento sistematiza a preocupação das professoras em suscitar no cotidiano das unidades de Educação Infantil a percepção de que a desigualdade reproduzida nesse espaço educativo é decorrente de desiguais relações de poder (SCOTT, 1995).

A construção do documento se deu em um momento peculiar, quando foram construídos os planos nacionais, estaduais e municipais de Educação e da maioria deles foram retirados os termos gênero e orientação sexual: "E foi um movimento bem interessante, porque foi bem, à época, da aprovação do Plano Municipal de Educação, que faria a extinção da nomenclatura de gênero; e, ao mesmo tempo, a gente lá e nos questionavam: "Então, vocês vão sustentar?" - "Sim, porque o que a gente está faẓendo é relações de gênero" (Elaine). Outras pesquisas também elucidam esse processo:

Para justificar essa exclusão, utilizam o pseudoconceito da 'ideologia de gênero' -, que ensinaria as crianças a não ter pertencimento identitário e acabaria com as famílias, criando um verdadeiro pânico em relação a essa temática. Pânico injustificado porque gênero não é uma ideologia, é um conceito que procura ampliar o debate sobre a qualidade da educação; democrática e acolhedora de todos e todas independente de seu pertencimento racial, étnico, religioso ou de gênero. A intenção não é ensinar como ser menino ou ser menina ou acabar com a família como uma instituição, mas acolher todas as formas de ser menino ou menina ou qualquer modelo de organização familiar (VIANNA, UNBEHAUM, 2016, p. 97).

Apesar desse movimento conservador, cada vez mais crescente no cenário brasileiro, e das tensões durante o processo de construção do documento, incluindo o fato de gênero ter tido menos visibilidade no documento, essa política, ao possibilitar uma prática da autoavaliação institucional participativa, ancorada na noção de qualidade como algo construído coletivamente, traz à tona, em meio a muitos desafios, questões de gênero para os sujeitos envolvidos no cuidado e na educação dos bebês e das crianças pequenas. 
Todavia, para a compreensão de como determinada política pública se configura, é preciso perguntar por seu processo de articulação, especialmente quando essa política busca romper com padrões estabelecidos. Em outras palavras, entender as estratégias, os jogos de poder, as relações de tensão, os sujeitos envolvidos na construção da política seria a chave central para a formulação de uma política.

Logo, para analisarmos a configuração estabelecida no momento da construção do documento, ainda nos perguntaremos: afinal, quem são essas profissionais que assumiram o desafio de inserir uma temática considerada polêmica, especialmente em um contexto histórico de retrocessos e discursos conservadores na política nacional? Nos termos de Elias, quem são essas que jogaram esses jogos de poder? Compreender a configuração estabelecida nesse contexto histórico não é encontrar uma lei que irá explicar esse fenômeno humano. Ao contrário, é entender as relações de poder que permearam todo o processo (ELIAS, 2008).

\section{Referências}

ACORDO Queerográfico. e-cadernosces. Disponível em:< http://eces.revues.org/1539>. Acesso em: 17 mai. 2017.

BONDIOLI, Anna. Dos indicadores às condições do projeto educativo: um percurso pedagógico-político de definição e garantia da qualidade das creches da Região da Emília-Romanha. In: (org.). $\mathbf{O}$ projeto pedagógico da creche e a sua avaliação: a qualidade negociada. Trad. Fernanda Landucci Ortale \& Ilse Paschoal Moreira. Campinas: Autores Associados, 2004 (Coleção Educação contemporânea).

BRASIL. Constituição Federal de 1988. Promulgada em 5 de outubro de 1988. Disponível em <http://www.planalto.gov.br/ccivil_03/constituicao/constituição.htm>.

Ministério da Educação/Secretaria da Educação Básica. Indicadores da Qualidade na Educação Infantil. Brasília: MEC/SEB, 2009.

. Ministério da Educação Secretaria de Educação Básica. Diretrizes Curriculares Nacionais para a Educação Infantil. Brasília: MEC/SEB, 2010.

ELIAS, Norbert. A sociedade dos indivíduos. Trad. Vera Ribeiro. Rio de Janeiro: Zahar, 1994. Introdução à Sociologia. Lisboa: Edições 70, 2008.

FARIA, Ana Lúcia Goulart de. Pequena infância, educação e gênero: subsídios para um estado da arte.

Cadernos Pagu, v. 26, p. 279-288, 2006. 
FARIA, Livia Monique de Castro; CASTANHEIRA, Marina Aparecida Marques. Na hora do banho: o borbulhar de relatos de violências sexuais contra crianças. In: Fazendo Gênero 10, 2013, Florianópolis. Anais... Florianópolis: UFSC, 2013. v. 1, p. 1-11. Disponível em: http://www.fg2013.wwc2017.eventos.dype.com.br/resources/anais/20/1373286888_ARQUIVO_Nahor adobanhooborbulharderelatosdeviolenciassexuaiscontracriancas.pdf. Acesso em 12/6/2017.

FINCO, Daniela. Educação infantil, espaços de confronto e convívio com as diferenças: análise das interações entre professoras e meninas e meninos que transgridem as fronteiras de gênero. Tese de Doutorado. Universidade de São Paulo, 2010.

; OLIVEIRA, Fabiana de Oliveira. A sociologia da pequena infância e a diversidade de gênero e de raça nas instituições de educação infantil. In: FARIA, Ana Lúcia Goulart de; FINCO, Daniela (Orgs.). Sociologia da infância no Brasil. Campinas, SP: Autores Associados, 2011.

RIBEIRO, Cláudia Maria. Gênero e sexualidade no cuidar e educar. Pátio - Educação Infantil. Ano VI, mar./jun., 2008, p. 10-13.

ROSEMBERG, Fúlvia. Políticas públicas e qualidade da educação infantil. In: UNBEHAUM, Sandra; ARTES, Amélia. Escritos de Fúlvia Rosemberg. São Paulo: Cortez: Fundação Carlos Chagas, 2015.

SÃO PAULO. Secretaria Municipal de Educação. Diretoria de Orientação Técnica. Indicadores de Qualidade da Educação Infantil Paulistana. São Paulo: SME / DOT, 2016 (versão final).

SCOT'T, J. W. Gênero: uma categoria útil de análise histórica. Educação e Realidade, Porto Alegre, v. 20, n. 2, jul./dez., 1995, p. 71-99.

VIANNA, Claudia Pereira; UNBEHAUM, Sandra. Contribuições da produção acadêmica sobre gênero nas políticas educacionais: elementos para repensar a agenda. CARREIRA, Denise et. al. Gênero e educação: fortalecendo uma agenda para as políticas educacionais. São Paulo: Ação Educativa, Cladem, Ecos, Geledés, Fundação Carlos Chagas. 2016, p. 55 - 120. 